\title{
Snow Water Equivalent of Dry Snow Derived From GNSS Carrier Phases
}

\author{
Patrick Henkel $^{\circledR}$, Member, IEEE, Franziska Koch ${ }^{\circledR}$, Florian Appel ${ }^{\circledR}$, Heike Bach ${ }^{\circledR}$, Monika Prasch ${ }^{\circledR}$, \\ Lino Schmid $^{\circledR}$, Jürg Schweizer ${ }^{\circledR}$, and Wolfram Mauser ${ }^{\circledR}$, Member, IEEE
}

\begin{abstract}
Snow water equivalent (SWE) is a key variable for various hydrological applications. It is defined as the depth of water that would result upon complete melting of a mass of snow. However, until now, continuous measurements of the SWE are either scarce, expensive, labor-intense, or lack temporal or spatial resolution especially in mountainous and remote regions. We derive the SWE for dry-snow conditions using carrier phase measurements from the Global Navigation Satellite System (GNSS) receivers. Two static GNSS receivers are used, whereby one antenna is placed below the snow and the other antenna is placed above the snow. The carrier phase measurements of both receivers are combined in double differences (DDs) to eliminate clock offsets and phase biases and to mitigate atmospheric errors. Each DD carrier phase measurement depends on the relative position between both antennas, an integer ambiguity due to the periodic nature of the carrier phase signal, and the SWE projected into the direction of incidence. The relative positions of the antennas are determined under snow-free conditions with millimeter accuracy using real-time kinematic positioning. Subsequently, the SWE and carrier phase integer ambiguities are jointly estimated with an integer least-squares estimator. We tested our method at an Alpine test site in Switzerland during the dry-snow season 2015-2016. The SWE derived solely by the GNSS shows very high correlation with conventionally measured snow pillow (root mean square error: $11 \mathrm{~mm}$ ) and manual snow pit data. This method can be applied to dense low-cost GNSS receiver networks to improve the spatial and temporal information on snow.
\end{abstract}

Index Terms-Carrier phase measurements, Global Positioning System (GPS), Real Time Kinematic (RTK), snow water equivalent (SWE), SnowSense.

Manuscript received May 23, 2017; revised October 25, 2017 and January 16, 2018; accepted January 20, 2018. Date of publication March 7, 2018; date of current version May 21, 2018. The work of P. Henkel, F. Koch, and F. Appel was supported by ESA through the ARTES-IAP Demo Project SnowSense under Grant 4000113149/14/NL/AD. (Patrick Henkel and Franziska Koch contributed equally to this work). (Corresponding authors: Patrick Henkel; Franziska Koch.)

P. Henkel is with the Institute for Communications and Navigation, Technische Universität München, 80333 Munich, Germany, and also with ANavS GmbH, 80798 Munich, Germany (e-mail: patrick.henkel@tum.de).

F. Koch, M. Prasch, and W. Mauser are with the Department of Geography, Ludwig-Maximilians-Universität München, 80333 Munich, Germany (e-mail: franziska.koch@lmu.de).

F. Appel and H. Bach are with Vista Remote Sensing in Geosciences GmbH, 80333 Munich, Germany.

L. Schmid and J. Schweizer are with the WSL Institute for Snow and Avalanche Research SLF, 7260 Davos, Switzerland.

Color versions of one or more of the figures in this paper are available online at http://ieeexplore.iee.org.

Digital Object Identifier 10.1109/TGRS.2018.2802494

\section{INTRODUCTION}

$\mathbf{T}$ HE Earth's water resources are stored to a great extent in permanent or seasonal snow cover. The amount of water stored in the snowpack expressed as snow water equivalent (SWE) is a key variable in water resources management and an essential component within the Earth's climate system [1]. The amount of snow and its melting determines quantitatively and temporally the river runoff of numerous mountain catchments. The snow cover is hence a naturally regulated storage which is relevant for many hydrological applications, such as hydropower production, navigation, water supply for drinking water, and irrigation [2]-[4]. Moreover, the release of water stored in the snowpack might contribute to avalanche formation, slush flows, and floods. The latter may in particular occur during the conditions of intense melting and rain in spring; their intensity and temporal occurrence may increase under changing climatic conditions [5], [6]. Continuous monitoring of the snowpack, especially the SWE, is therefore highly requested for hydrological modeling approaches as well as avalanche and in particular flood forecasts.

However, until now, measurements of SWE are very scarce, especially in difficult to reach and sparsely populated areas, and are often not conducted continuously. Conventionally, the SWE is measured by weighing a given volume of snow cut out of the snowpack with tubes [7]. This technique is so far the most reliable method, but it is destructive, as snow pits have to be dug, and labor-intense, and gives only a snapshot in time. Snow pillows [8] and snow scales, for example, measure continuously, but are quite expensive and difficult to install and are limited to flat terrain. Moreover, these methods are prone to measurement errors due to bridging effects, especially during the first wetting of snow in spring [9]. Regarding in situ measurements, further research is ongoing. A novel in situ measurement approach was recently described by Rashmi et al. [10] who applied a radar reflectometry method to derive the SWE with P-band signals. Active and passive microwave remote sensing approaches, e.g., summarized by Tedesco [11], provide spatial information on snow height but also on the SWE. However, they are often not available in high-temporal resolution, may lack the required spatial resolution, or are restricted due to foreshortening or layover effects, in particular in mountain regions [12]. To overcome some of these problems, the recently started NASA SnowEx airborne campaign [13] looks promising as it employs a 
microwave multisensor approach, including L-band interferometry, Ka-band radar altimetry, as well as volume scattering techniques to derive the SWE. In general, continuous and high-quality measurements at numerous locations would be largely useful for the validation of Earth observation satellite data and to improve hydrological models. Since the last decade, several approaches to derive snow cover properties from the L-band Global Navigation Satellite System (GNSS) signals have been developed. These are in particular GNSS reflectometry approaches, mainly based on fix installed, highend geodetic receivers, aiming to derive information on snow height as the signals are reflected at the air-snow interface [14]-[18]. Moreover, Yu et al. [19] estimated snow depth based on a multipath phase combination of triple-frequency signals. For the reflectometry techniques, mainly the GNSS signal strength information stemming from the combined reception of line-of-sight and reflected paths is applied and a quite flat area of up to $1 \mathrm{~km}^{2}$ is needed [20], whereby the antenna is situated in the middle. Koch et al. [21] developed an alternative approach using low-cost Global Positioning System (GPS) receivers to quantitatively derive the liquid water content in the snowpack from the attenuation of the carrier-to-noise-power density ratio $\mathrm{C} / \mathrm{N}_{0}$ caused by a prominent change of the dielectric properties of snow as liquid water occurs. In addition, this approach, in combination with an upward-looking ground penetrating radar system, provides snow height and SWE information under dry snow and wet snow [22]. Evaluating the two-way travel time information of the electromagnetic pulse in the same L-band frequency domain had already shown good results for snow properties, as long as the snowpack was dry but overestimated the snow height under wet-snow conditions [23]. This deficiency was improved by the combination with the GPS system [22]. However, radar sensors are expensive and thus not attractive for dense sensor networks.

A novel and highly promising method to derive the SWE with low-cost GNSS sensors, which is presented in this paper, was developed and applied within the ARTES-IAP Demo Project SnowSense (https://artesapps.esa.int/projects/snowsense-dp), co-funded by the European Space Agency (ESA). In general, this project aims to provide highly demanded continuous and nondestructive information on snow cover properties, also in remote and difficult to access areas, e.g., for hydropower companies and flood or avalanche forecast centers. In order to make dense sensor networks possible, all sensors are low-cost encompassing two GNSS receivers and antennas, a microcontroller, and data storage. One of these setups using low-cost GPS sensors (recording L1-band GPS signals) was used for this paper at the high-alpine test site Weissfluhjoch near Davos, Switzerland, at an elevation of $2.540 \mathrm{~m}$ a.s.l. In addition, an optional self-sufficient energy component as well as a component for data transmission are available for the SnowSense GNSS sensor setup. However, regarding the latter, for this paper, the infrastructure of the test site with its electric grid and its internet facility was used.

We show, exemplarily for the dry winter period 2015-2016, that with this GNSS setup, the SWE can continuously be

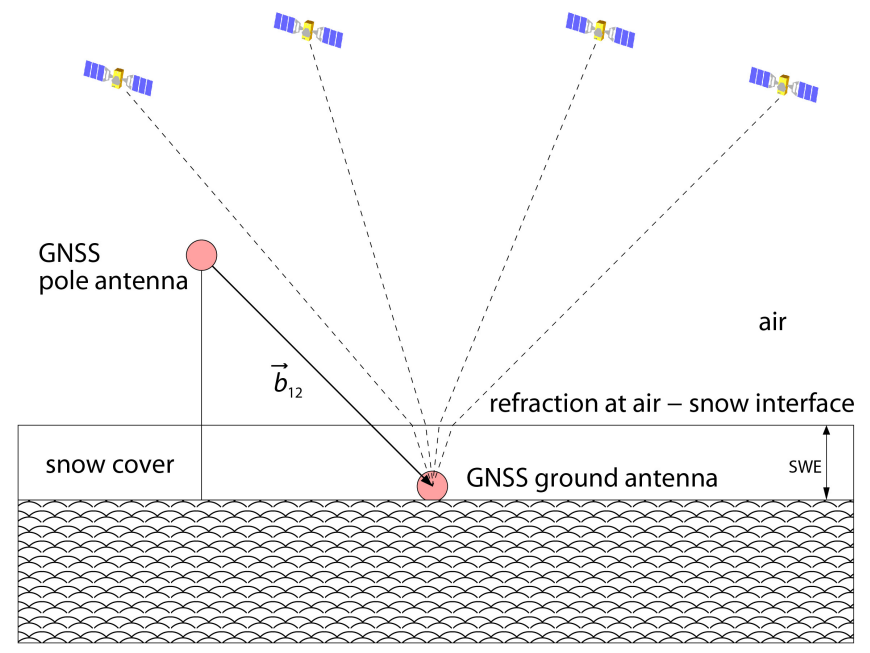

Fig. 1. GNSS setup for derivation of SWE.

determined solely with GNSS carrier phase signals, which are, compared with GNSS $\mathrm{C} / \mathrm{N}_{0}$ recordings, highly sensitive to changes in the SWE.

\section{Modeling of Carrier Phases With Snow Cover}

The snow causes a delay in both pseudorange and carrier phase measurements which is proportional to the SWE under dry-snow conditions. However, we use only GNSS carrier phase measurements, as the pseudorange measurements are too noisy to be beneficial for SWE determination.

In general, snow has two effects on the carrier phase, which are taken into account in our model:

1) the delay of GNSS signals due to reduced signal propagation speed in snow;

2) angular refraction/bending at air-snow interface due to a change in medium.

First, the snow-induced signal delay can be derived from the phase measurements using a precise model of the phase measurements and the proposed integer least-squares estimator. It is the most sophisticated part as the phase measurements are also affected by several other parameters (e.g., the receiver's and satellite's position, integer ambiguities, and atmospheric delays) and since all parameters need to be determined with a total error of at most a few centimeters. Second, the refraction at the air-snow interface is derived from Snell's Law.

The focus of this paper is on SWE determination, i.e., receiver and satellite clock offsets and biases, orbital errors, and atmospheric errors are all nuisance parameters. Therefore, we eliminate all nuisance parameters by performing differential measurements using two low-cost GNSS antennas connected to two low-cost GNSS receivers. Thereby, one antenna is placed on a pole above the snow and one antenna on the ground as shown in Fig. 1.

The carrier phase measurements of the continuous GNSS waves are provided directly by the phase-locked loop of the GNSS receiver [24]. Differential carrier phases between the pairs of receivers and satellites are determined and the obtained double difference (DD) measurements are modeled 
for receiver pair $r \in\{1,2\}$ and satellite pair $\{k, l\}$ by

$$
\begin{aligned}
\lambda \varphi_{12}^{k l}= & \lambda\left(\varphi_{1}^{k}-\varphi_{2}^{k}\right)-\lambda\left(\varphi_{1}^{l}-\varphi_{2}^{l}\right) \\
= & \left(\vec{e}^{k l}\right)^{\mathrm{T}} \vec{b}_{12}+c_{12}^{k l}+\lambda N_{12}^{k l}+\lambda / 2 \Delta N_{12}^{k l} \\
& +v_{a} \cdot \Delta t_{s}^{k l}+\lambda \Delta \varphi_{\mathrm{MP}, 12}^{k l}+\varepsilon_{12}^{k l}
\end{aligned}
$$

with the wavelength $\lambda$, the phase measurement $\varphi_{r}^{k}$ recorded in cycles, the normalized line-of-sight vector $\vec{e}^{k}$ between the antenna phase centers of the satellites and the receivers, the baseline vector $\vec{b}_{12}$ between the pole and ground antennas, the synchronization correction $c_{12}^{k}$, the integer ambiguity $N_{r}^{k}$, the half cycle slip $\Delta N_{r}^{k} / 2$ due to the periodicity of the carrier phase, the speed of light in air $v_{a}$, the snow induced time delay $\Delta t_{s}^{k}$, the phase multipath $\Delta \varphi_{\mathrm{MP}, r}^{k}$ due to simultaneous reception of multiple propagation paths, and the phase noise $\varepsilon_{r}^{k}$, and

$$
(\cdot)^{k l}=(\cdot)^{k}-(\cdot)^{l}
$$

being the difference between satellites $k$ and $l$. We assume a short baseline length of only a few meters such that different tropospheric and ionospheric delays, as described in [25], are negligible.

Phase multipath includes reflections from surrounding obstacles and the snow-ground and the air-snow interfaces (mainly for the upper antenna). The phase multipath error is bounded by $\lambda / 4$ as shown in [24] and might be higher at grazing incidence [26]. As the direct signal is assumed to be much stronger than the reflected ones in our application, the multipath error is typically in the order of less than $2 \mathrm{~cm}$ and is mapped to the noise, i.e.,

$$
\tilde{\varepsilon}_{12}^{k l}:=\lambda \Delta \varphi_{\mathrm{MP}, 12}^{k l}+\varepsilon_{12}^{k l} .
$$

The extra-time delay $\Delta t_{s}^{k l}$ due to snow can be expressed in terms of a snow parameter $d_{s}$. It can be interpreted as a vertical distance that can be expressed in two manners. On the one side, it describes the travel time that a signal would need through the snowpack. It is decomposed into two components. The first component $\Delta t_{a}^{v}$ refers to the travel time for the vertical distance $d_{s}$ that would arise in the absence of snow. The second component $\Delta t_{s}^{v}$ describes the extra delay caused by the snow. On the other side, the distance $d_{s}$ can be expressed in terms of the travel time that a signal would need in air. Both distances are set equal

$$
d_{s}:=v_{s} \cdot\left(\Delta t_{a}^{v}+\Delta t_{s}^{v}\right) \stackrel{!}{=} v_{a} \Delta t_{a}^{v}
$$

with the speed of light in air $v_{a}$ and the speed of light in snow $v_{s}$, respectively.

Solving for the extra delay $\Delta t_{s}^{v}$ due to snow and projecting it into the range domain using the speed of light in air $v_{a}$ give

$$
v_{a} \Delta t_{s}^{v}=\left(\frac{v_{a}}{v_{s}}-1\right) d_{s}=: \gamma\left(v_{s}\right) d_{s}
$$

where the speed correction factor $\gamma\left(v_{s}\right)$ is implicitly defined by the second identity. The GNSS signals are typically received from an elevation of less than $90^{\circ}$. Therefore, the vertical delay is mapped into a slant delay. As differential measurements are used for snow monitoring, the slant delay is differentiated between satellites $k$ and $l$

$$
v_{a} \Delta t_{s}^{k l}:=m^{k l} \cdot v_{a} \Delta t_{s}^{v}=m^{k l} \cdot \gamma\left(v_{s}\right) d_{s} .
$$

This slant delay is linearly proportional to the snow parameter $d_{s}$, which itself is linearly proportional to the SWE. The single difference mapping function in (6) is given by

$$
m^{k l}=\frac{1}{\sin \left(E_{s}^{k}\right)}-\frac{1}{\sin \left(E_{s}^{l}\right)}
$$

with $E_{s}^{k}$ and $E_{s}^{l}$ being the elevations of the refracted signals of the $k$ th and $l$ th satellite, respectively, under the assumption of a flat and horizontal surface. The elevation of this refracted signal can be obtained from Snell's law as

$$
E_{s}^{k}=90^{\circ}-a \sin \left(\frac{n_{a}}{n_{s}} \sin \left(90^{\circ}-E_{a}^{k}\right)\right)
$$

with $E_{a}^{k}$ being the satellite's elevation above the snow cover for the $k$ th satellite, and $n_{a}$ and $n_{s}$ being the refraction indices in the air and the snow. For this approach, we set the elevation mask to $25^{\circ}$ to eliminate satellites with excessive phase multipath and frequent losses of phase lock and to discard near grazing incidence observations. The elevation mask implies the sampling area in terms of a horizontal radius around the antenna.

The speed of light in air $v_{a}$ is assumed to be the speed of light in vacuum $c$ and the speed of light in dry snow is set to $v_{s} \approx 2.3 \times 10^{8} \mathrm{~ms}^{-1}$, which was also applied in [22] and [23] and is directly linked to the dielectric properties of dry snow. Moreover, $v_{s}$ can be determined by using the permittivity of snow $\varepsilon_{s}^{\prime}$ and applying Snell's law as

$$
v_{s}=\frac{n_{a}}{n_{s}} v_{a} \text { with } n_{s}=\sqrt{\varepsilon_{s}^{\prime}} .
$$

In general, $v_{s}$ also depends on the density of dry snow [23]. However, as the dry snow density has only a negligible influence on the permittivity of snow [21], [27] compared with the liquid water content, the chosen value of $v_{s}$ sufficiently covers a wide range of dry snow densities.

The snow-related term $\Delta t_{s}^{k l}$ is obtained from the DD phase measurements by subtraction of the estimates of the baseline term, the synchronization correction, the integer ambiguities, and the cycle slips. The obtained term is typically called carrier phase residuals. If there is no snow, then the residuals are close to zero-mean white Gaussian noise with a standard deviation of less than $1 \mathrm{~cm}$. If a snow pack exists, then the residuals are linearly proportional to both the mapping function $m^{k l}$ and the snow parameter $d_{s}$.

\section{Method For SWE Derivation}

In this section, we describe in detail our method for the SWE derivation with the GNSS. As the GNSS antennas are mounted at static points, it is sufficient to determine the 3-D baseline vector only once and to reuse this known baseline for SWE derivation at every subsequent epoch. As a snow-free reference measurement, we determined the 3-D baseline vector directly after the installation of the receivers without any snow cover. Thus, the positioning can be separated from the estimation of the snow parameter. This setup without any snow cover refers to carrier-phase relative positioning, so-called Real Time Kinematic (RTK) or postprocessed kinematic positioning, which was described by Talbot [28]. An efficient implementation was developed by Takasu and Yasuda [29]. 
The performance has been improved over the last two decades, e.g., by using multi-GNSS measurements and fixing ambiguities of multiple constellations (e.g., joint GPS/Globalnaya navigatsionnaya sputnikovaya sistema (Glonass) fixing [30] and joint GPS/quasi-zenith satellite system fixing (QZSS) [31]), by code multipath estimation [32], by partial ambiguity fixing for faster fixing [33], and/or by partial integer decorrelation [34].

Fig. 2 includes a flowchart for determining the SWE. The steps in black solid boxes are identical to the ones of the standard RTK positioning. The synchronization correction is needed for low-cost GNSS receivers and computed according to Henkel and Cárdenas [35]. Cycle slips are obtained by the prediction of measurements from history and by the comparison of these predicted measurements with actual measurements. The steps in blue dashed boxes are specific to snow and explained in this section. For this approach, we used GPS L1-band recordings with a sampling rate of $1 \mathrm{~Hz}$, which is a reasonable tradeoff between maximizing the accuracy through a large number of measurements and minimizing the computational effort. In addition, the method can also be applied to any other GNSS system (i.e., Galileo, GLONASS, and Beidou) and/or other frequencies, or the combinations of systems and/or frequencies.

\section{A. Fixing of Initial Ambiguities}

We are using only carrier phase observations (i.e., no pseudorange measurements), which are ambiguous. We correct the DD measurements $\lambda \varphi_{12}^{k l}$ of (1) for the a priori known baseline $\vec{b}_{12}$, the synchronization error $c_{12}^{k l}$, and half cycle slips $\lambda / 2 \Delta N_{12}^{k l}$, i.e.,

$$
\begin{aligned}
\lambda \tilde{\varphi}_{12}^{k l} & :=\lambda \varphi_{12}^{k l}-\left(\vec{e}^{k l}\right)^{\mathrm{T}} \vec{b}_{12}-c_{12}^{k l}-\lambda / 2 \Delta N_{12}^{k l} \\
& =\lambda N_{12}^{k l}+\gamma m^{k l} \cdot d_{s}+\tilde{\varepsilon}_{12}^{k l}
\end{aligned}
$$

which leaves only the ambiguities $N_{12}^{k l}$ and the snow parameter $d_{s}$ as unknowns. The combined phase noise and multipath $\tilde{\varepsilon}_{12}^{k l}$ is typically below $2 \mathrm{~cm}$ for all satellites. The standard deviation of the combined phase noise and multipath was estimated from the sum of the squared measurement residuals using a short time series of a few seconds. These measurement residuals represent the difference between the measurements and the best linear least-squares fit of these measurements.

The separation of $N_{12}^{k l}$ and $d_{s}$ can be performed only via the known mapping function, which changes over time with the satellite elevation. Therefore, we consider the corrected DD measurements from $n$ epochs jointly

$$
\left(\begin{array}{c}
\lambda \tilde{\varphi}_{12}^{k l}\left(t_{1}\right) \\
\vdots \\
\lambda \tilde{\varphi}_{12}^{k l}\left(t_{n}\right)
\end{array}\right)=H^{k l}\left(\begin{array}{c}
N_{12}^{k l} \\
d_{s}
\end{array}\right)+\left(\begin{array}{c}
\tilde{\varepsilon}_{12}^{1 l}\left(t_{1}\right) \\
\vdots \\
\tilde{\varepsilon}_{12}^{K l}\left(t_{n}\right)
\end{array}\right)
$$

with

$$
H^{k l}=\left(\begin{array}{cc}
\lambda & \gamma m^{k l}\left(t_{1}\right) \\
\vdots & \vdots \\
\lambda & \gamma m^{k l}\left(t_{N}\right)
\end{array}\right) .
$$

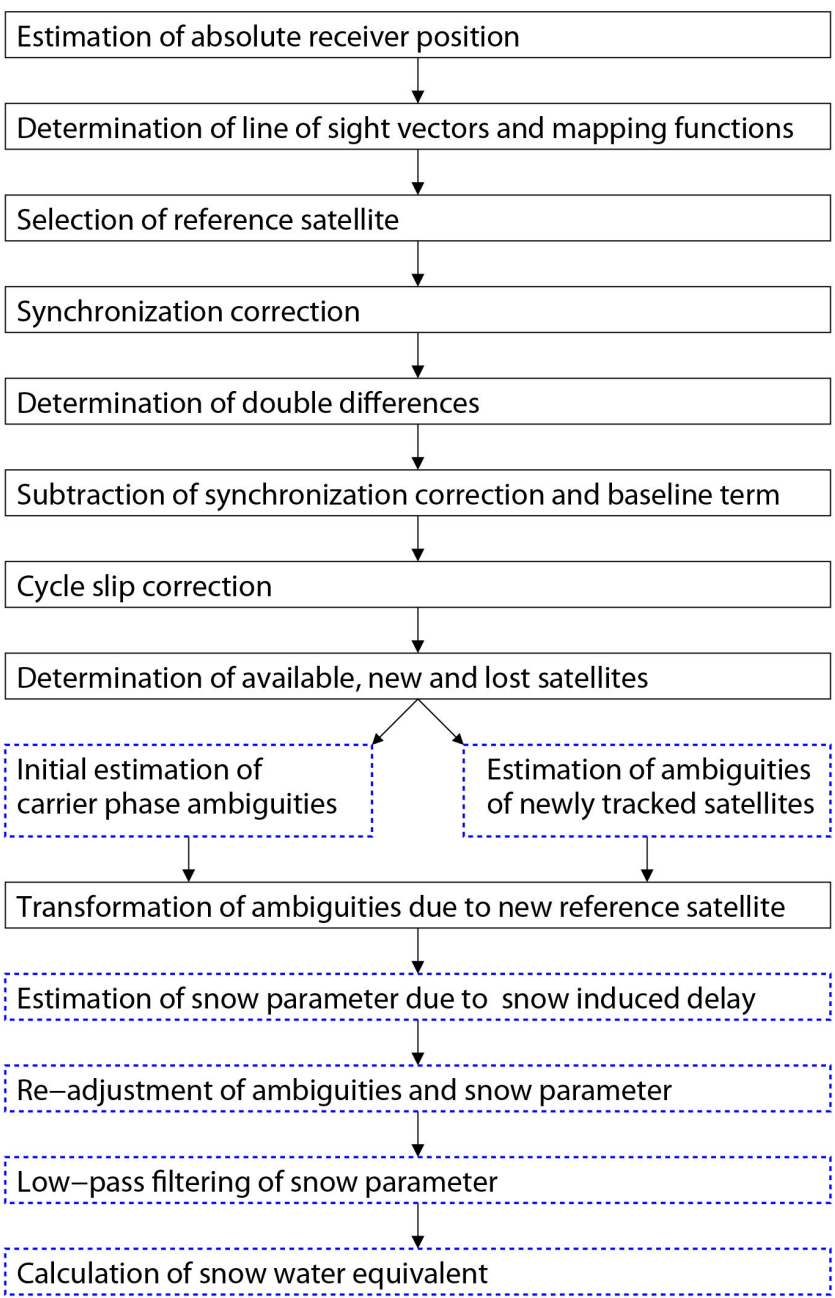

Fig. 2. Flowchart for individual processing steps aiming to derive the SWE. The steps in blue/dashed boxes are specific to snow.

The least-squares estimates of the ambiguities and the snow parameter follow as:

$$
\begin{aligned}
\left(\begin{array}{c}
\hat{N}_{12}^{k l} \\
\hat{d}_{s}
\end{array}\right) & =\arg \min _{N_{12}^{k l}, d_{s}}\left\|\left(\begin{array}{c}
\lambda \tilde{\varphi}_{12}^{k l}\left(t_{1}\right) \\
\vdots \\
\lambda \tilde{\varphi}_{12}^{k l}\left(t_{n}\right)
\end{array}\right)-H^{k l}\left(\begin{array}{c}
N_{12}^{k l} \\
d_{s}
\end{array}\right)\right\|^{2} \\
& =\left(\left(H^{k l}\right)^{T} H^{k l}\right)^{-1}\left(H^{k l}\right)^{T}\left(\begin{array}{c}
\lambda \tilde{\varphi}_{12}^{k l}\left(t_{1}\right) \\
\vdots \\
\lambda \tilde{\varphi}_{12}^{k l}\left(t_{n}\right)
\end{array}\right)
\end{aligned}
$$

The sum of squared residuals of this least-squares adjustment is given by

$$
\operatorname{SSE}_{12}^{k l}=\left\|P_{H}^{\perp}\left(\begin{array}{c}
\lambda \tilde{\varphi}_{12}^{k l}\left(t_{1}\right) \\
\vdots \\
\lambda \tilde{\varphi}_{12}^{k l}\left(t_{n}\right)
\end{array}\right)\right\|^{2}
$$

with $P_{H}^{\perp}$ being the projector on the space orthogonal of $H^{k l}$. If the sum of squared phase residuals is sufficiently small and the ambiguity estimate is close to an integer number, the ambiguity can be fixed by rounding off to the nearest 
integer number, i.e.,

$$
\check{N}_{12}^{k l}=\operatorname{round}\left(\hat{N}_{12}^{k l}\right) \text {. }
$$

The snow parameter occurs as common variable for all DDs in (11). Thus, the snow parameter couples the DDs of all satellites. The estimation of both, $N_{12}^{k l}, k \in\{1, \ldots, K\}$, and $d_{s}$, can be improved by a joint consideration of the measurements from all visible satellites and available epochs. Therefore, (11) is expanded to

$$
\left(\begin{array}{c}
\lambda \tilde{\varphi}_{12}^{1 l}\left(t_{1}\right) \\
\vdots \\
\lambda \tilde{\varphi}_{12}^{1 l}\left(t_{n}\right) \\
\vdots \\
\lambda \tilde{\varphi}_{12}^{K l}\left(t_{1}\right) \\
\vdots \\
\lambda \tilde{\varphi}_{12}^{K l}\left(t_{n}\right)
\end{array}\right)=H\left(\begin{array}{c}
N_{12}^{1 l} \\
\vdots \\
N_{12}^{K l} \\
d_{s}
\end{array}\right)+\left(\begin{array}{c}
\tilde{\varepsilon}_{12}^{1 l}\left(t_{1}\right) \\
\vdots \\
\tilde{\varepsilon}_{12}^{1 l}\left(t_{n}\right) \\
\vdots \\
\tilde{\varepsilon}_{12}^{K l}\left(t_{1}\right) \\
\vdots \\
\tilde{\varepsilon}_{12}^{K l}\left(t_{n}\right)
\end{array}\right)
$$

with

$$
H=\left(\begin{array}{ccc|c}
\lambda & & \gamma m^{1 l}\left(t_{1}\right) \\
\vdots & & & \vdots \\
\lambda & & \gamma m^{1 l}\left(t_{n}\right) \\
\hline & \ddots & & \vdots \\
\hline & & \gamma m^{K l}\left(t_{1}\right) \\
& & \vdots & \vdots \\
& & \gamma m^{K l}\left(t_{n}\right)
\end{array}\right) .
$$

The least-squares solution of the DD integer ambiguities and snow parameter is given by

$$
\begin{aligned}
& \left(\check{N}_{12}^{1 l}, \ldots, \check{N}_{12}^{K l}, \check{d}_{s}\right)^{T} \\
& =\arg \min _{\substack{\left\{N_{12}^{1 l}, \ldots, N_{12}^{K l}\right\} \\
d_{s} \in \mathbb{R}}}\left\|\lambda \tilde{\varphi}_{12}-H\left(\begin{array}{c}
N_{12}^{1 l} \\
\vdots \\
\frac{N_{12}^{K l}}{d_{s}}
\end{array}\right)\right\|_{\Sigma^{-1}}^{2}
\end{aligned}
$$

where the phase measurements of all epochs and satellites are stacked as

$$
\begin{aligned}
& \lambda \tilde{\varphi}_{12}=\left(\lambda \tilde{\varphi}_{12}^{1 l}\left(t_{1}\right), \ldots, \lambda \tilde{\varphi}_{12}^{1 l}\left(t_{n}\right), \ldots\right. \\
& \left.\lambda \tilde{\varphi}_{12}^{K l}\left(t_{1}\right), \ldots, \lambda \tilde{\varphi}_{12}^{K l}\left(t_{n}\right)\right)^{T} .
\end{aligned}
$$

The solution of (18) can be obtained with an integer leastsquares estimator, e.g., the Least-squares ambiguity decorrelation (LAMBDA) adjustment method of Teunissen [36], which includes an integer decorrelation $Z$ and sequential tree search $\mathcal{S}$ to fix the ambiguities to integers. The $i$ th candidate of the search is given by

$$
\check{N}_{12}^{(i)}=\left(\begin{array}{c}
\check{N}_{12}^{1 l} \\
\vdots \\
\check{N}_{12}^{K l}
\end{array}\right)=Z^{-1} \mathcal{S}^{(i)}\left(Z \hat{N}_{12}\right)
$$

with

$$
\hat{N}_{12}=\left(\begin{array}{c}
\hat{N}_{12}^{1 l} \\
\vdots \\
\hat{N}_{12}^{K l}
\end{array}\right)
$$

A fixing is typically considered as reliable if the sum of squared ambiguity residuals of the second-best candidate $\check{N}_{12}^{(2)}$ are significantly larger than the sum of squared ambiguity residuals of the first-best candidate $\check{N}_{12}^{(1)}$. This ratio test $q$ is given by

$$
q=\frac{\left\|\hat{N}_{12}-\check{N}_{12}^{(2)}\right\|^{2}}{\left\|\hat{N}_{12}-\check{N}_{12}^{(1)}\right\|^{2}} \gg 1
$$

and was analyzed in detail for future GNSS ambiguity resolution by Verhagen and Teunissen [37]. Once the initial ambiguities are fixed, an instantaneous estimate of the snow parameter can be obtained at every epoch by

$$
\begin{aligned}
& \check{d}_{s}\left(t_{n}\right)=\frac{1}{m^{T}\left(t_{n}\right) \Sigma^{-1}\left(t_{n}\right) m\left(t_{n}\right)} \\
& \cdot m^{T}\left(t_{n}\right) \Sigma^{-1}\left(t_{n}\right)\left(\begin{array}{c}
\lambda\left(\tilde{\varphi}_{12}^{1 l}\left(t_{n}\right)-\check{N}_{12}^{1 l}\right) \\
\vdots \\
\lambda\left(\tilde{\varphi}_{12}^{K l}\left(t_{n}\right)-\check{N}_{12}^{K l}\right)
\end{array}\right)
\end{aligned}
$$

with

$$
m\left(t_{n}\right)=\gamma \cdot\left(\begin{array}{c}
m^{1 l}\left(t_{n}\right) \\
\vdots \\
m^{K l}\left(t_{n}\right)
\end{array}\right) .
$$

\section{B. Initialization of Ambiguities of Newly Tracked Satellites}

The ambiguities of newly tracked satellites need to be initialized. We distinguish between initializations after short signal interruptions (e.g., due to loss of phase lock) and long signal interruptions (e.g., rise of satellite above horizon). For short signal interruptions, the ambiguities can be instantaneously fixed using the phase measurements at the previous epoch $n-1$ and the change of the mapping function, i.e.,

$$
\begin{aligned}
& \check{N}_{12}^{k l}=\operatorname{round}\left(\hat{N}_{12}^{k l}\right) \quad \text { with } \\
& \hat{N}_{12}^{k l}=\tilde{\varphi}_{12}^{k l}\left(t_{n}\right)-\frac{m^{k l}\left(t_{n}\right)}{m^{k l}\left(t_{n-1}\right)}\left(\tilde{\varphi}_{12}^{k l}\left(t_{n-1}\right)-\check{N}_{12}^{k l}\left(t_{n-1}\right)\right) .
\end{aligned}
$$

For longer signal interruptions, the likelihood of undetected cycle slips and/or of a change in the snow parameter increases. Therefore, the ambiguities are fixed using the current snow parameter estimate, i.e.,

$$
\check{N}_{12}^{k l}=\operatorname{round}\left(\frac{1}{\lambda}\left(\lambda \tilde{\varphi}_{12}^{k l}\left(t_{n}\right)-\gamma \cdot m^{k l}\left(t_{n}\right) \check{d}_{s}\left(t_{n}\right)\right)\right) \text {. }
$$

\section{Readjustment of Ambiguities}

The tracking errors of the receivers and/or errors in the cycle slip correction might require a readjustment of the ambiguities. We consider two options for this readjustment.

The first option can be applied if a satellite is having approximately the same elevation as the reference satellite. In this case, the differential mapping function $m^{k l}$ vanishes and the ambiguity of the satellite can be simply readjusted as

$$
\check{N}_{12}^{k l}=\operatorname{round}\left(\tilde{\varphi}_{12}^{k l}\left(t_{n}\right)\right) \text {. }
$$

The second option is a least-squares reestimation of ambiguities and snow parameter according to (13). In general, 

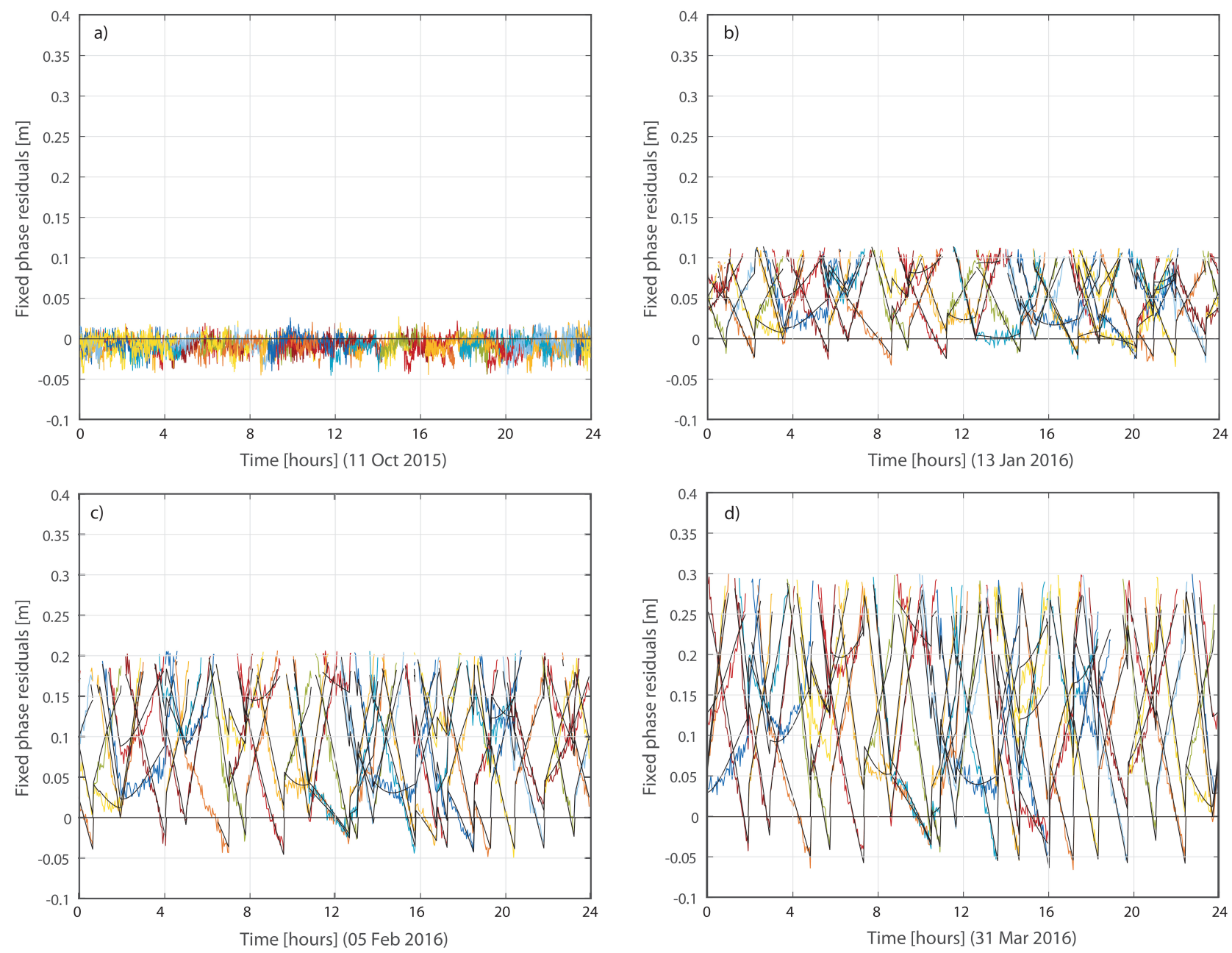

Fig. 3. Carrier phase residuals for each GPS satellite recorded over one day for (a) snow-free conditions (October 11, 2015) with small fixed phase residuals around zero. Carrier phase residuals and arcs for each GPS satellite recorded over one day for dry-snow conditions with an SWE of approximately (b) 200 mm (January 13, 2016), (c) $400 \mathrm{~mm}$ (February 5, 2016), and (d) $600 \mathrm{~mm}$ (March 31, 2016).

the first option is clearly preferred, since it is much more accurate. However, there are some satellite passes with an elevation maximum far below the elevation of the reference satellite. In this case, a readjustment can only be performed with the second option.

\section{Fixed Phase Residuals}

After the ambiguities are fixed, $r_{12}^{k l}$ remains as

$r_{12}^{k l}\left(t_{n}\right)=\lambda \tilde{\varphi}_{12}^{k l}\left(t_{n}\right)-\lambda \check{N}_{12}^{k l}=\gamma m^{k l}\left(t_{n}\right) \cdot \check{d}_{s}\left(t_{n}\right)+\tilde{\varepsilon}_{12}^{k l}\left(t_{n}\right)$.

Regarding (28), the fixed phase residuals $r_{12}^{k l}$ encompass the snow terms $\gamma m^{k l} \cdot \check{d}_{s}$ and $\tilde{\varepsilon}_{12}^{k l}$.

Fig. 3 illustrates the carrier phase residuals of all 32 GPS satellites recorded during one day for four exemplary days with different values of the SWE with approximately 0, 200, 400 , and $600 \mathrm{~mm}$. The starting point and the ending point of each satellite are given by the time of satellite rising and setting and, thus, is almost independent of snow cover. Each color corresponds to one of the 32 GPS satellites.

There are four different types of dynamics in the residuals. First, random short-term variations over a few seconds are caused by phase noise. Second, short-term to midterm oscillations lasting several minutes could be multipath. Third, midterm variations over a few hours are caused by the change of the satellite elevation. Finally, long-term variations over several hours or days are caused by the changes of the snowpack. Clearly, the last type is dominant once the SWE exceeds a certain minimum and leads to the typical arched shape.

The minimum of the carrier phase residuals is reached when the satellites reach their maximum elevation angle. The residuals of satellites serving as a reference satellite are equal to zero due to the DD approach, and residuals of satellites, which have temporally even a higher elevation than the reference satellite, show negative values. An example is given in Fig. 4 for a time period of approximately $5 \mathrm{~h}$ for the passing of four reference satellites and their corresponding refracted elevation angles over the unrefracted mask of $25^{\circ}$ corresponding to a refracted angle of approximately $44.2^{\circ}$. Each change of the reference satellite is indicated with a vertical black dashed line. We require a minimum of $60^{\circ}$ for the unrefracted signal (corresponding to an elevation of approximately $67.4^{\circ}$ for the refracted signal) of a satellite to be chosen as reference satellite. Once a satellite falls below this minimum elevation, the satellite with the highest elevation is chosen as new reference satellite. 

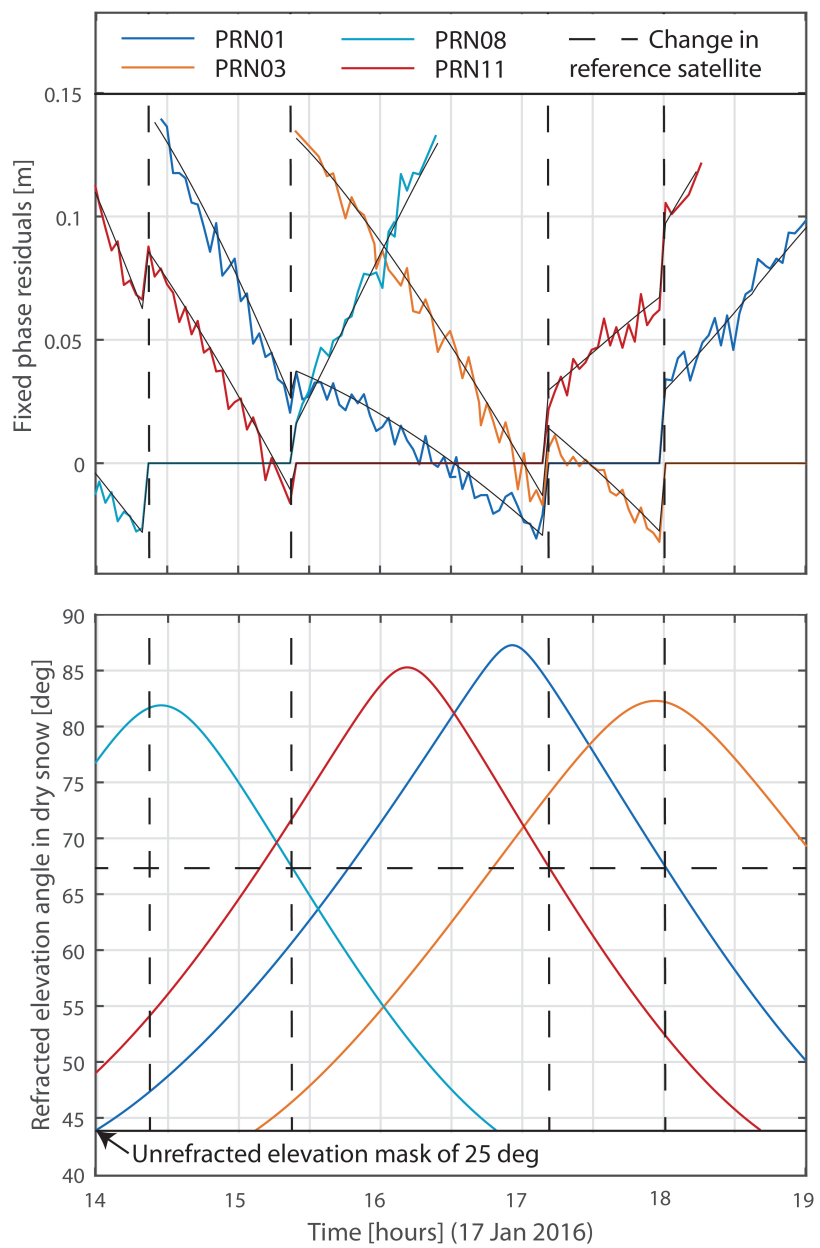

Fig. 4. (a) Fixed phase residuals with arcs, exemplary shown for four different satellites serving temporally as reference satellites, recorded over a time period of approximately $5 \mathrm{~h}$ on January 17, 2016. The black lines are the arcs of the fitted phases. (b) Corresponding refracted elevation in the dry snow of those four satellites.

\section{E. Filtering of Snow Parameter Estimate}

The precision of the least-squares snow parameter estimate can be obtained from (23) as

$$
\sigma_{\check{d}_{s}\left(t_{n}\right)}=\frac{1}{\sqrt{m^{T}\left(t_{n}\right) \Sigma^{-1}\left(t_{n}\right) m\left(t_{n}\right)}}
$$

and simplifies for a diagonal measurement covariance matrix to

$$
\sigma_{\breve{d}_{s}\left(t_{n}\right)}=\frac{1}{\gamma \sqrt{\sum_{k=1}^{K} \frac{\left(m^{k l}\right)^{k}}{\left(\sigma_{\varphi}^{k l}\right)^{2}}}} .
$$

This standard deviation of the snow parameter depends on the following factors:

1) accuracy of DD carrier phase measurements $\left(\sigma_{\varphi} \leq 1 \mathrm{~cm}\right)$

2) difference of mapping functions $m^{k l}$;

3) speed correction factor $\gamma=c_{0} / v_{s}-1 \approx 0.3$.

Fig. 5 shows the scaling $1 /\left(\gamma \mathrm{m}^{k l}\right)$ of the measurement noise standard deviation. The scaling is lowest if the difference between the elevation of a satellite and the elevation of

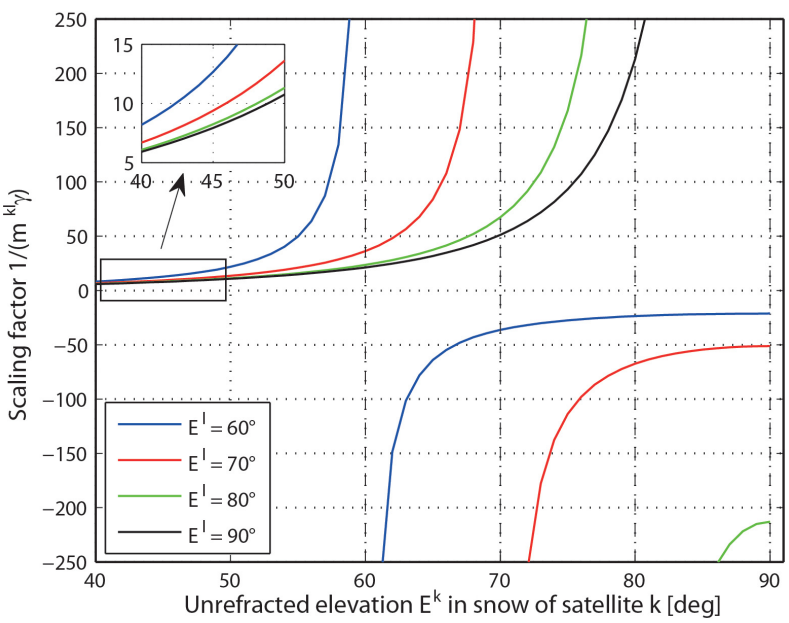

Fig. 5. Snow parameter determination: scaling of phase noise by mapping function and speed correction factor for four different elevations of a potential reference satellite $l$. The elevation of satellite $k$ is shown on the $x$-axis and the elevation of the reference satellite $l$ is shown in the legend.

the reference satellite is maximum. Consequently, the ideal measurement satellite should be as low as possible, if the reference satellite is taken as high as possible. In this case, the scaling factor varies between 5 and 10 depending on the elevation of the reference satellite. The scaling factor quickly increases with smaller elevation differences between the considered satellite and the reference satellite. This large scaling factor makes the single-epoch snow parameter estimate very noisy and requires some filtering.

The fixed phase measurements can be described by some arcs parametrized by the snow parameter and mapping function. We can obtain such fitted arcs by least-squares estimation of the snow parameter based on given fixed phase measurements and mapping functions. As the phase measurements of some satellites might be corrupted by receiver tracking errors or azimuthal inhomogeneities in the snow cover, we perform the fitting for each satellite pass separately, i.e.,

$$
\begin{aligned}
& r_{12, \text { fitted }}^{k l}=\gamma \tilde{m}^{k l} \cdot \arg \min _{d_{s}}\left\|r_{12}^{k l}-\gamma \tilde{m}^{k l} \cdot d_{s}\right\|^{2} \\
& =\tilde{m}^{k l} \cdot \frac{1}{\left(\tilde{m}^{k l}\right)^{T} \tilde{m}^{k l}}\left(\tilde{m}^{k l}\right)^{T} r_{12}^{k l}
\end{aligned}
$$

with the stacked phase measurements of epochs $t_{1}$ to $t_{n}$

$$
r_{12}^{k l}=\left(\begin{array}{c}
r_{12}^{k l}\left(t_{1}\right) \\
\vdots \\
r_{12}^{k l}\left(t_{n}\right)
\end{array}\right)
$$

and the stacked mapping functions

$$
\tilde{m}^{k l}=\left(\begin{array}{c}
m^{k l}\left(t_{1}\right) \\
\vdots \\
m^{k l}\left(t_{n}\right)
\end{array}\right) .
$$

We use only the satellites with a good agreement of the fixed phase measurements and fitted arcs of (31), i.e.,

$$
\sum_{j=1}^{n}\left\|r_{12}^{k l}\left(t_{j}\right)-r_{12, \text { fitted }}^{k l}\left(t_{j}\right)\right\|^{2} \leq \chi^{2}
$$


with $\chi^{2}$ being an upper bound on the sum of squared deviations. In addition to the fixed phase residuals, Fig. 3 shows the estimated arcs for each satellite in black for days with snow cover. Fig. 4 proposes an enlarged view of the residuals for a few hours. The fitted arcs were derived from the raw measurements and mapping functions under the assumption of a constant snow parameter. Nevertheless, an excellent match can be observed between residuals and arcs.

The accuracy of the snow parameter can be further improved by a joint consideration of the fitted arcs from all satellites with good fitting. Therefore, we replace the "raw" measurements in (23) by the fitted arcs and consider only the subset of satellites with sufficiently accurate arc fitting, i.e.,

$$
\begin{array}{r}
\check{d}_{s, \text { fitted }}\left(t_{n}\right)=\frac{1}{m_{s}^{T}\left(t_{n}\right) \Sigma_{s}^{-1}\left(t_{n}\right) m_{s}\left(t_{n}\right)} \cdot m_{s}^{T}\left(t_{n}\right) \Sigma_{s}^{-1}\left(t_{n}\right) \\
\cdot\left(\begin{array}{c}
r_{12, \text { fitted }}^{1 l}\left(t_{n}\right) \\
\vdots \\
r_{12, \text { fitted }}^{K l}\left(t_{n}\right)
\end{array}\right)
\end{array}
$$

where the lower index $s$ denotes the subset of satellites with sufficiently small sum of squared residuals.

Finally, $\breve{d}_{s \text {,fitted }}$ is low-pass filtered to reduce jumps in the case of lost or newly tracked satellites. Thus, the final snow parameter estimate is given by

$$
\overline{\breve{d}}_{s, \text { fitted }}\left(t_{n}\right)=\frac{1}{\tau} \check{d}_{s, \text { fitted }}\left(t_{n}\right)+\left(1-\frac{1}{\tau}\right) \check{d}_{s, \text { fitted }}\left(t_{n-1}\right)
$$

with $\tau$ being the time constant of the low-pass filter. For this approach, $\tau$ was set to $4 \mathrm{~h}$. Alternatively, the estimate $\breve{d}_{s, \text { fitted }}\left(t_{n}\right)$ could be obtained also from the combination of the individual snow parameter estimates of each arc using the standard deviations of the snow parameter estimates in the weighting, as proposed in (4) in Tabibi et al. [38]. However, (35) and (36), in their current form, have the advantage that they can also be applied very efficiently with large data sets.

\section{F. Calculation of $S W E$}

In a final step, the SWE is derived from the final snow parameter estimate of (35) using the underlying model of (6). The final snow parameter estimate is multiplied by the speed correction factor $\gamma$ to obtain SWE

$$
\operatorname{SWE}\left(t_{n}\right)=\gamma \cdot \overline{\breve{d}}_{s, \text { fitted }}\left(t_{n}\right) \cdot 1000[\mathrm{~mm}] .
$$

\section{RESUlts AND DiscusSION}

We applied this approach for our GNSS measurement setup at the test site Weissfluhjoch for the entire dry-snow season from October 1, 2015 to April 1, 2016. After the latter date, the first significant wetting of the snowpack occurred, and the snowpack was not considered as dry any more. The test site is equipped with numerous meteorological and snow sensors [22], [39]. We compared our measurements with SWE data recorded with a snow pillow and to manual measurements from weekly to biweekly snow profiles. The temporal resolution of the GNSS output data was reduced to one SWE value per $30 \mathrm{~min}$ to be temporally comparable with the continuous

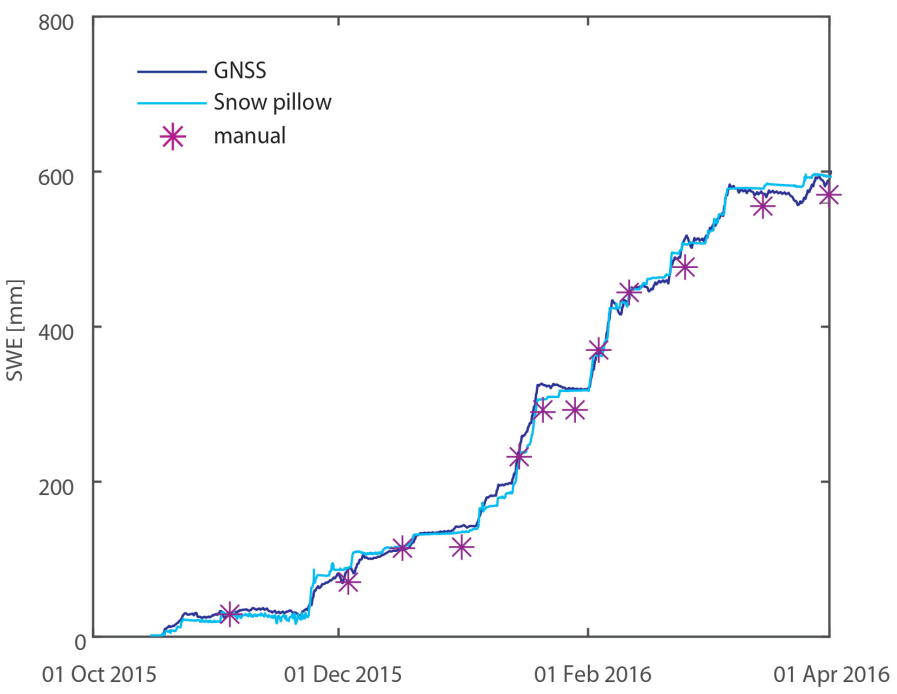

Fig. 6. SWE derived by GNSS carrier phase residuals compared with measurements recorded with a snow pillow and to manual snow pit measurements; all data from the test site Weissfluhjoch during the dry-snow season 2015-2016.

SWE in situ reference measurements taken in parallel with the snow pillow. The snow pillow and the GNSS system ran continuously without any breakdown.

Fig. 6 shows the evolution of the GNSS-derived SWE (dark blue line) and the SWE measured by the snow pillow (light blue line). The weekly to biweekly manual snow profile measurements are indicated with magenta stars. The distance between the GNSS measurements and the snow pillow is $20 \mathrm{~m} \mathrm{[22].} \mathrm{The} \mathrm{snow} \mathrm{profiles} \mathrm{including} \mathrm{the} \mathrm{manual} \mathrm{measure-}$ ments were performed in the vicinity of the two continuous measurements. The manual measurements cannot be taken at the same location during one winter period as the snowpack is destroyed after a measurement. Therefore, the snow profiles were conducted along three profile lines in a distance to the GPS measurements of approximately 5-20 m, depending on the location of the snow profiles taken at a specific date.

In general, all three SWE measurements provide similar results. The continuous recordings of the snow pillow and GNSS show a very similar temporal evolution and similar absolute values. Small deviations between these two measurement methods might be due to small-scale spatial variability caused by slightly different precipitation amounts and/or wind conditions, even though they are located close to each other at the same test site. The manual SWE measurements fit well with the values obtained with the two continuous measurement methods. However, in general, the manually measured values are slightly lower than the continuous measurements, which might also be related to small-scale spatially variable snow properties at the test site. On some days, the agreement is better than on others. The reason for the observed difference in agreement might be related to the fact that the profile location varied in the course of the winter, being sometimes closer to the location of the continuous measurements, sometimes further away.

Table I summarizes the statistics for the comparison of the three SWE measurement methods. The methods show high agreement indicated by the values of $R^{2}$ close to 1 . Regarding 
TABLE I

STATISTICS OVERVIEW OF THE COMPARISON OF SWE DERIVED BY GNSS and Measured by SnOW Pillow and WeEkLY to BiWeEKLY Manually MEasured in SnOW Pits at THE TeSt Site WEISSFLUHJOCH FOR THE DRY-SNOW WINTER PERIOD 2015-2016

\begin{tabular}{|c||c||c||}
\hline & $\mathrm{R}^{2}$ & RMSE $[\mathrm{mm}]$ \\
\hline GNSS - Snow pillow & 0.999 & 10.6 \\
\hline GNSS - manual & 0.995 & 23.4 \\
\hline Snow pillow - manual & 0.997 & 24.0 \\
\hline
\end{tabular}

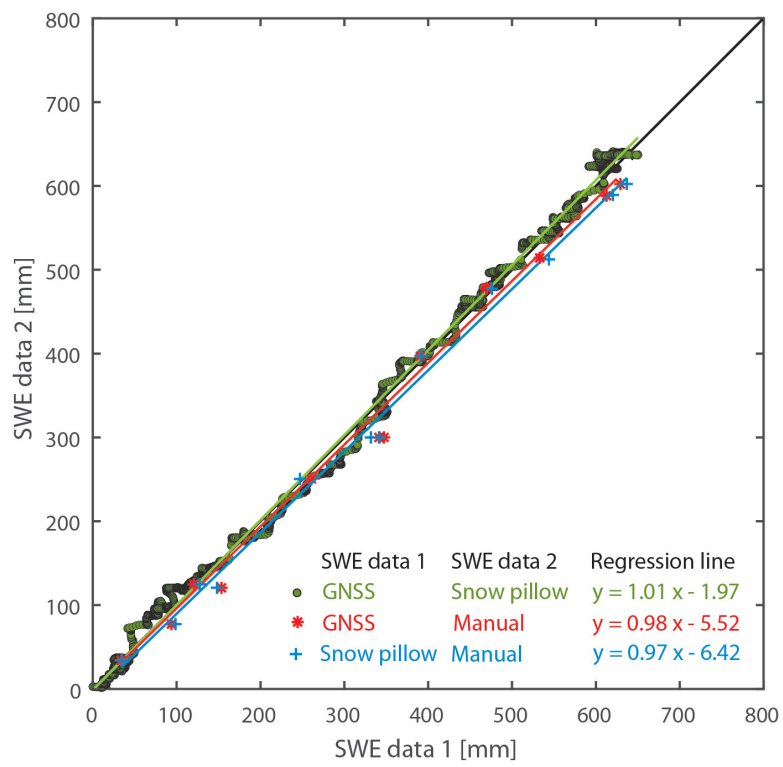

Fig. 7. Linear regression between, in each case, two of the three SWE methods GNSS, snow pillow, and manual. Black solid line indicates 1:1 line.

the root mean square error (RMSE), the two continuous measurements GNSS and snow pillow fit the best; the RMSE is very low, approximately $11 \mathrm{~mm}$. The RMSE between manual measurements and GNSS or snow pillow measurements is, in both the cases about $23-24 \mathrm{~mm}$, low as well. The high degree of agreement between the methods is also shown by the regression lines in Fig. 7. GNSS-derived snow estimation and snow pillow data are very close to the 1:1 line.

The proposed GNSS method enables continuous and nondestructive determination of SWE for dry-snow conditions. Important advantages of our GNSS approach, especially compared with snow pillow measurements, are that only lowcost GNSS sensors are used and that they only need a little space for installation, whereas snow pillows are expensive and consist of 3-m diameter bladder containing approximately $800 \mathrm{~L}$ of an antifreeze solution, which needs to be installed with concrete at a flat area. Moreover, the heat flux between the snow pillow surface might not be adequate to the heat flux of the soil and the bottom of the snowpack [40], and as already mentioned, the snow pillow measurements are potentially prone to errors due to bridging effects in the snowpack, especially during the transition of dry- to wet-snow conditions [9]. In contrast, the GNSS system is not affected by disturbing heat fluxes or bridging effects as the signals travel nondestructively through the snow. However, as we only considered dry snow during the observed time period, no bridging effects at the snow pillow occurred. Regarding manual snow pit measurements in snow profiles, they represent the most reliable conventional method up to now, but are destructive and performed (bi)weekly at the best. In summary, our results of GNSS-derived values of the SWE suggest that with this novel method, it is possible to determine the SWE with high accuracy and at low costs.

In general, the following points have to be considered for obtaining highly precise GNSS-derived values of the SWE. It is important to determine the baseline between both GNSS antennas very accurately with our RTK model under snow-free conditions. An error in distance between the antennas of only $2.5 \mathrm{~cm}$ would lead to an error in the SWE of approximately $50 \mathrm{~mm}$. Therefore, it is very important to accurately process the carrier phase data also under snow-free conditions and to filter the baseline estimate to reduce the impact of phase noise and multipath. Moreover, it is important to tightly tense the pole with the upper antenna, e.g., with ropes, so that it cannot be markedly affected by vibrations or positional changes, e.g., due to wind effects. However, if a shift of one antenna occurs, it is possible to reestimate the baseline using RTK. Moreover, the GNSS signals of at least a minimum of four GNSS satellites have to be received at both the antennas to estimate the SWE. This is fulfilled at almost any place on Earth, due to the global GNSS satellite constellations. However, limiting constraints in receiving signals from the minimum amount of GNSS satellites might occur in extremely deep valleys or very steep slopes.

Finally, this paper was performed during dry-snow conditions with continuous L1-band phase tracking at high $\mathrm{C} / \mathrm{N}_{0}$ values. As shown, a very accurate SWE was obtained also at high SWE values. After Maetzler [41], the penetration depth of L-band microwaves can theoretically reach a few hundred meters under dry-snow conditions. However, the penetration depth decreases markedly under wet-snow conditions, which was also investigated by Schleppe and Lachapelle [42] for lowcost GPS receivers under moist and compact avalanche snow conditions. The phase processing during wet-snow conditions is beyond the scope of this paper and will be considered in our future work. Phase processing becomes increasingly difficult during wet-snow conditions as signal attenuation increases markedly with increasing liquid water content and changing dielectric properties [21]. GNSS signal strength information as already applied in [21] and [22] has to be additionally considered in an integrated GNSS carrier phase and signal strength processing.

\section{CONCLUSION}

The SWE was continuously derived for dry-snow conditions solely based on carrier phase measurements of GNSS receivers. Two static GNSS receivers were used to determine DD GNSS carrier phase measurements. A precise snowspecific model was developed for these DD measurements, which takes the delay of GNSS signals in snow due to the reduced signal propagation speed and the refraction processes, as well as the relative position between both GNSS antennas using RTK positioning, and the carrier phase integer ambiguities into account. The carrier phase integer ambiguities and 
the SWE were jointly estimated using an integer least-squares estimator. After ambiguity fixing, we analyzed the fixed phase residuals that depend on snow, phase noise, and multipath. The snow-dependent part is proportional to the SWE and an elevation-dependent mapping function. We applied a lowpass filter to reduce phase noise and multipath and, thereby, to improve the accuracy of the SWE.

The proposed method was tested with two low-cost GPS receivers installed at the high Alpine test site at Weissfluhjoch in Switzerland during the dry-snow winter season 2015-2016. The SWE measurements of a snow pillow with a temporal resolution of $30 \mathrm{~min}$ served as continuous reference. Our GNSS-derived SWE data show a high degree of agreement in absolute values and temporal evolution with this reference. The weekly to biweekly performed manual SWE measurements in snow pits also agree well with our GNSS-derived values.

Advantages of the proposed method are, e.g., that it does not require manual measurements, are globally applicable and it does not disrupt the snow cover. Moreover, the baseline can be recalculated in the presence of a snow cover if the SWE is precisely known at the time of recalculation. The reliability of integer ambiguity fixing and the accuracy of the SWE can be further improved by using multi-GNSS instead of GPS-only measurements, i.e., by additionally including Galileo, GLONASS, and/or Beidou measurements. The use of low-cost sensors is sufficient, which enables dense sensor networks. Thereby, snow information with high-spatial and high-temporal resolution can be derived for entire river basins allowing for more accurate runoff and flood prediction. The global availability of GNSS signals enables measurements also in remote locations where conventional measurements are scarce. In many regions, especially in high mountain regions and the large areas of the Tundra, Taiga, and Arctic, it is very valuable to gain information on the snow accumulated during the entire dry-snow winter period. Currently, our setup is installed at various remote test sites in Newfoundland involving first demo users within the scope of the ARTESIAP Demo Project SnowSense.

\section{ACKNOWLEDGMENT}

The authors would like to thank several staff members of the WSL Institute for Snow and Avalanche Research SLF who performed the manual snow profile measurements at the test site Weissfluhjoch.

\section{REFERENCES}

[1] D. G. Vaughan et al., "Observations: Cryosphere," in Climate Change 2013: The Physical Science Basis. Contribution of Working Group I to the Fifth Assessment Report of the Intergovernmental Panel on Climate Change. Cambridge, U.K.: Cambridge Univ. Press, 2013, pp. 317-382.

[2] T. P. Barnett, J. C. Adam, and D. P. Lettenmaier, "Potential impacts of a warming climate on water availability in snow-dominated regions," Nature, vol. 438, no. 7066, pp. 303-309, 2005.

[3] F. Koch, M. Prasch, H. Bach, W. Mauser, F. Appel, and M. Weber, "How will hydroelectric power generation develop under climate change scenarios? A case study in the Upper Danube basin," Energies, vol. 4, no. 10 , pp. $1508-1541,2011$.

[4] W. Mauser and M. Prasch, Regional Assessment of Global Change Impacts: The Project GLOWA-Danube. London, U.K.: Springer, 2015.
[5] M. Bavay, M. Lehning, T. Jonas, and H. Löwe, "Simulations of future snow cover and discharge in Alpine headwater catchments," Hydrol. Process., vol. 23, no. 1, pp. 95-108, 2009.

[6] I. T. Stewart, "Changes in snowpack and snowmelt runoff for key mountain regions," Hydrol. Process., vol. 23, no. 1, pp. 78-94, 2009.

[7] C. Fierz et al., "The international classification for seasonal snow on the ground," UNESCO-IHP, Paris, France, Tech. Rep., 2009, vol. 25.

[8] D. Archer and D. Stewart, "The installation and use of a snow pillow to monitor snow water equivalent," Water Environ. J., vol. 9, no. 3, pp. 221-230, 1995.

[9] J. B. Johnson and D. Marks, "The detection and correction of snow water equivalent pressure sensor errors," Hydrol. Process., vol. 18, no. 18, pp. 3513-3525, 2004

[10] R. Shah et al., "Remote sensing of snow water equivalent using P-band coherent reflection," IEEE Geosci. Remote Sens. Lett., vol. 14, no. 3 , pp. 309-313, Mar. 2017.

[11] M. Tedesco, Remote Sensing of the Cryosphere. Hoboken, NJ, USA: Wiley, 2014.

[12] T. Strozzi, A. Wiesmann, and C. Mätzler, "Active microwave signatures of snow covers at 5.3 and $35 \mathrm{GHz}$," Radio Sci., vol. 32, no. 2 , pp. 479-495, 1997.

[13] E. Kim et al. (2017). Overview of SnowEx Year 1 Activities. [Online]. Available: https://ntrs.nasa.gov/search.jsp?R=20170007518

[14] K. M. Larson, E. D. Gutmann, V. U. Zavorotny, J. J. Braun, M. W. Williams, and F. G. Nievinski, "Can we measure snow depth with GPS receivers?" Geophys. Res. Lett., vol. 36, no. 17, pp. L17502-1-L17502-5, 2009.)

[15] M. D. Jacobson, "Inferring snow water equivalent for a snow-covered ground reflector using GPS multipath signals," Remote Sens., vol. 2, no. 10 , pp. 2426-2441, 2010

[16] E. Cardellach, F. Fabra, O. Nogues-Correig, S. Oliveras, S. Ribó, and A. Rius, "GNSS-R ground-based and airborne campaigns for ocean, land, ice, and snow techniques: Application to the GOLD-RTR data sets," Radio Sci., vol. 46, no. 6, pp. RS0C04-1-RS0C04-16, 2011.

[17] N. Rodriguez-Alvarez et al., "Snow thickness monitoring using GNSS measurements," IEEE Geosci. Remote Sens. Lett., vol. 9, no. 6, pp. 1109-1113, Nov. 2012.

[18] S. Jin and N. Najibi, "Sensing snow height and surface temperature variations in Greenland from GPS reflected signals," Adv. Space Res., vol. 53, no. 11, pp. 1623-1633, 2014.

[19] K. Yu, W. Ban, X. Zhang, and X. Yu, "Snow depth estimation based on multipath phase combination of GPS triple-frequency signals," IEEE Geosci. Remote Sens. Lett., vol. 53, no. 9, pp. 5100-5109, Sep. 2015.

[20] K. M. Larson, "GPS interferometric reflectometry: Applications to surface soil moisture, snow depth, and vegetation water content in the western United States," Wiley Interdiscipl. Rev., Water, vol. 3, no. 6, pp. 775-787, 2016.

[21] F. Koch, M. Prasch, L. Schmid, J. Schweizer, and W. Mauser, "Measuring snow liquid water content with low-cost GPS receivers," Sensors, vol. 14, no. 11, pp. 20975-20999, 2014.

[22] L. Schmid et al., "A novel sensor combination (upGPR-GPS) to continuously and nondestructively derive snow cover properties," Geophys. Res. Lett., vol. 42, no. 9, pp. 3397-3405, 2015.

[23] L. Schmid et al., "Continuous snowpack monitoring using upwardlooking ground-penetrating radar technology," J. Glaciol., vol. 60, no. 221, pp. 509-525, 2014.

[24] P. Misra and P. Enge, Global Positioning System: Signals, Measurements and Performance, 2nd ed. Lincoln, MA, USA: Ganga-Jamuna Press, 2006.

[25] S. D. P. Williams and F. G. Nievinski, "Tropospheric delays in ground-based GNSS multipath reflectometry-Experimental evidence from coastal sites," J. Geophys. Res., Solid Earth, vol. 122, no. 3, pp. 2310-2327, 2017.

[26] F. G. Nievinski and K. M. Larson, "Forward modeling of GPS multipath for near-surface reflectometry and positioning applications," GPS Solutions, vol. 18, no. 2, pp. 309-322, 2014.

[27] A. Sihvola, E. Nyfors, and M. Tiuri, "Mixing formulae and experimental results for the dielectric constant of snow," J. Glaciol., vol. 31, no. 108, pp. $163-170,1985$.

[28] N. C. Talbot, "Centimeters in the field, a users perspective of realtime kinematic positioning in a production environment," in Proc. 6th Int. Tech. Meeting Satellite Division Inst. Navigat. (ION GPS), Salt Lake City, UT, USA, 1993, pp. 1049-1057.

[29] T. Takasu and A. Yasuda, "Development of the low-cost RTK-GPS receiver with an open source program package RTKLIB," in Proc. Int. Symp. GPS/GNSS, Jeju, South Korea, Nov. 2009, pp. 1-6. 
[30] P. Henkel, U. Mittmann, and M. Iafrancesco, "Real-time kinematic positioning with GPS and GLONASS," in Proc. 24th Eur. Signal Process. Conf. (EUSIPCO), Budapest, Hungary, Aug./Sep. 2016, pp. 1063-1067.

[31] N. Kubo, F. Wu, and A. Yasuda, "Integral GPS and QZSS ambiguity resolution," Trans. Jpn. Soc. Aeronautical Space Sci., vol. 47, no. 155, pp. 38-43, 2004.

[32] P. Henkel, M. Iafrancesco, and A. Sperl, "Precise point positioning with multipath estimation," in Proc. ION/IEEE Position, Location Navigat. Symp. (PLANS), Savannah, GA, USA, Apr. 2016, pp. 144-149.

[33] P. J. G. Teunissen, "On the GPS double-difference ambiguities and their partial search spaces," in Geodetic Theory Today. Berlin, Germany: Springer, 1995, pp. 39-48.

[34] P. Henkel and C. Günther, "Partial integer decorrelation: Optimum tradeoff between variance reduction and bias amplification," J. Geodesy, vol. 84, p. 51, Jan. 2010.

[35] P. Henkel and J. M. Cárdenas, "Method for determining a baseline between two receivers," European Patent 2749900 A1, Jul. 2, 2014.

[36] P. J. G. Teunissen, "The least-squares ambiguity decorrelation adjustment: A method for fast GPS integer ambiguity estimation," J. Geodesy, vol. 70, no. 1, pp. 65-82, 1995.

[37] S. Verhagen and P. J. G. Teunissen, "The ratio test for future GNSS ambiguity resolution," GPS Solutions, vol. 17, no. 4, pp. 535-548, 2013.

[38] S. Tabibi, F. Geremia-Nievinski, and T. van Dam, "Statistical comparison and combination of GPS, GLONASS, and multi-GNSS multipath reflectometry applied to snow depth retrieval," IEEE Geosci. Remote Sens. Lett., vol. 55, no. 7, pp. 3773-3785, Jul. 2017

[39] C. Marty and R. Meister, "Long-term snow and weather observations at Weissfluhjoch and its relation to other high-altitude observatories in the Alps," Theor. Appl. Climatol., vol. 110, no. 4, pp. 573-583, 2012

[40] J. B. Johnson and G. L. Schaefer, "The influence of thermal, hydrologic, and snow deformation mechanisms on snow water equivalent pressure sensor accuracy," Hydrol. Process., vol. 16, no. 18, pp. 3529-3542, 2002.

[41] C. Mäetzler, "COST action 712: Microwave radiometry," in Remote Sens. Atmos. Ocean from Space: Models, Instruments Techniques, F. S. Marzano and G. Visconti, Eds. Springer, 2002, pp. 231-246.

[42] J. Schleppe and G. Lachapelle, "Tracking performance of a HSGPS receiver under avalanche deposited snow," GPS Solutions, vol. 12, no. 1, pp. 13-21, 2006.

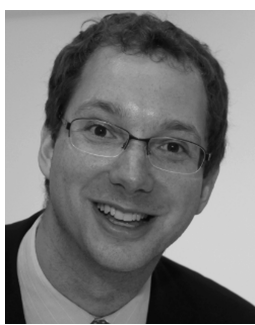

Patrick Henkel (M'03) received the bachelor's and master's degrees from the Technische Universität München (TUM), Munich, Germany, and the Ph.D. degree (summa cum laude) on reliable carrier phase processing from TUM, in 2010. He is currently pursuing the habilitation in precise point positioning at TUM.

He visited the Mathematical Geodesy and Positioning Group, Delft University of Technology, Delft, The Netherlands, in 2007, and the GPS Laboratory, Stanford University, Stanford, CA, USA, in 2008 and 2010. He is one of the founders and currently the Managing Director of ANavS GmbH, Munich.

Dr. Henkel received the Pierre Contensou Gold Medal in 2007, the first prize in Bavaria at the European Satellite Navigation Competition in 2010, and the Vodafone Award for his dissertation in 2011.

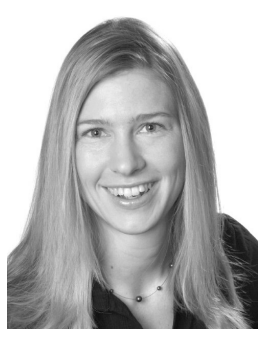

Franziska Koch received the Diplom (M.Sc.) degree in physical geography with remote sensing and the Ph.D. degree from the Ludwig-MaximiliansUniversität München (LMU), Munich, Germany, in 2009 and 2017, respectively.

She has been with the Department of Geography, LMU, since 2009, where she has been involved in studies aiming to derive environmental properties with Global Navigation Satellite System (GNSS) signals and hydrological modeling and climate change impact studies. From 2012 to 2016, she was visiting the WSL Institute for Snow and Avalanche Research SLF, Davos, Switzerland, during several short-term stays. She currently holds a postdoctoral position with the European Space Agency (ESA) IAP Demo Project SnowSense. Her research interests include the development and validation of GNSS microwave remote sensing algorithms to derive information of the snow cover and snow hydrological and other land surface processes.

Dr. Koch received the ESA Integ Space Award in 2013 along with her team members: H. Bach, W. Mauser, and F. Appel.

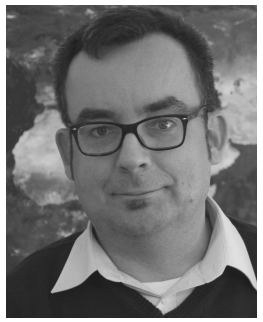

Florian Appel received the Diplom (M.Sc.) degree in physical geography with remote sensing from the Ludwig-Maximilians-Universität München (LMU), Munich, Germany, in 2000, with a focus on geography, hydrology, geophysics, and remote sensing.

In 2000, he started as a Project Scientist with Vista Remote Sensing in Geosciences GmbH, Munich, where he is currently responsible for research and development of operational services in hydrology. He currently serves as a Senior Scientist for several projects funded by the European Space Agency, German Aerospace Center, European Union, and national projects with main emphasizes on hydrology, such as snow and energy applications, earth observation services, and business. He has been a member of the Board of Directors of Polar View Earth Observation Ltd. Oxfordshire, U.K. since 2011. He is currently the Project Manager of the ESA IAP SnowSense Demonstration Project.

Mr. Appel received the ESA Integ Space Award in 2013 along with his team members: H. Bach, W. Mauser, and F. Koch.

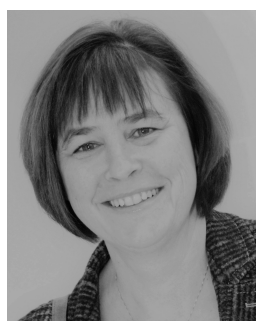

Heike Bach received the Diplom (M.Sc.) degree in hydrology from the University of Freiburg, Freiburg im Breisgau, Germany, in 1990, and the $\mathrm{Ph} . \mathrm{D}$. degree in geosciences from the LudwigMaximilians-Universität München, Munich, Germany, in 1995.

She is a specialist in both optical and Synthetic Aperture Radar data, and the development and implementation of new algorithms for earth observation analysis. She has co-developed both the radiative transfer model soil-leaf-canopy (SLC) and the multiphysics model process of mass and energy transfer (PROMET). She is the Founder and the Executive Director of Vista Remote Sensing in Geosciences $\mathrm{GmbH}$, Munich, a company specialized in the application of remotely sensed data for hydrology and agriculture, where she is currently a Project Manager for European Space Agency's (ESA) Food Security Thematic Exploitation Platform.

Dr. Bach received the ESA Integ Space Award in 2013 along with her team members: W. Mauser, F. Appel, and F. Koch.

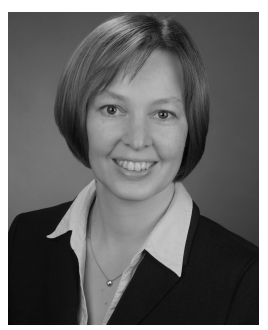

Monika Prasch received the Diplom (M.Sc.) and $\mathrm{Ph} . \mathrm{D}$. degrees in physical geography from the Ludwig-Maximilians-Universität München (LMU), Munich, Germany, in 2004 and 2010, respectively.

She has been with the Department of Geography, LMU, since 2006, where she holds a post-doctoral position in snow and ice modeling, and the analysis of climate change impacts and adaptation strategies. She is a member of the leading group of a transdisciplinary project to support the transition to renewable energies on a regional scale. Her research interests include hydrological and climate change impact modeling, and energy transition processes.

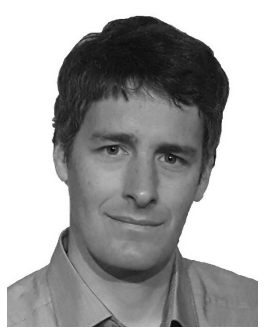

Lino Schmid received the M.Sc. degree in information technology and electrical engineering and the $\mathrm{Ph} . \mathrm{D}$. degree from ETH Zürich, Zürich, Switzerland, in 2010 and 2015, respectively.

He installed and maintained several radar sensors in the Swiss Alps and in remote locations like Greenland. He currently holds a post-doctoral position at the WSL Institute for Snow and Avalanche Research SLF, Davos, Switzerland. He develops algorithms to derive snow properties with L-band radar systems. His research interests include the derivation of snow properties, including snow height, liquid water content, snow water equivalent, and snowpack stratigraphy with radar systems. 


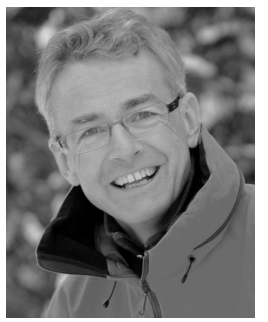

Jürg Schweizer received the M.Sc. degree in environmental physics and the Ph.D. degree in glaciology from ETH Zürich, Zürich, Switzerland, in 1985 and 1989, respectively

In 1990, he joined the WSL Institute for Snow and Avalanche Research SLF, Davos, Switzerland. He was with the Department of Civil Engineering, University of Calgary, Calgary, AB, Canada, from 1995 to 1996 . He moved back to the WSL Institute for Snow and Avalanche Research SLF, where he started the research group Formation of Alpine Natural Hazards in 2006. Since 2011, he has been leading the research unit Snow Avalanches and Prevention, at SLF. He was a Lecturer with ETH Zürich. From 2013 to 2017, he was the President of the Cryospheric Sciences Division, European Geosciences Union, Munich, Germany. He is currently the Head of the WSL Institute for Snow and Avalanche Research SLF, and a member of the Directorate of the Federal Research Institute WSL, Birmensdorf, Switzerland. His research interests include snow mechanics and avalanche formation, avalanche release, snow stability evaluation, avalanche forecasting, risk management, avalanche education, and rescue.

Dr. Schweizer received a Canada International Research Fellowship from the National Science and Engineering Council. From 2013 to 2017, he was the Editor-in-Chief of Cold Regions Science and Technology.

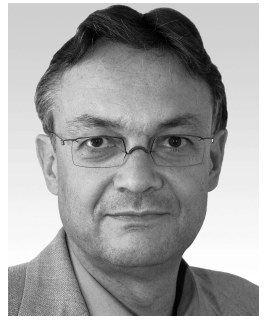

Wolfram Mauser (M'92) received the M.Sc. degrees in experimental physics and geography/hydrology and the Ph.D. degree from the University of Freiburg, Freiburg im Breisgau, Germany, in 1979,1981 , and 1984 , respectively.

In 1981, he was with the University of Maryland, College Park, MD, USA, and the Goddard Space Flight Center, Greenbelt, MD, USA, in the field of remote sensing and hydrology. From 1984 to 1991, he was an Assistant Professor with the Department of Hydrology, Institute for Physical Geography, University of Freiburg. In 1991, he was appointed as a Full Professor for geography and geographical remote sensing with the Department of Geography, Ludwig-Maximilians-Universität München, Munich, Germany. He is currently a Principal Investigator (PI) for the Shuttle Radar Topography Mission and SMOS mission. His research interests include the development of spatially distributed land surface process models, new sensors technologies, and image processing algorithms and model assimilation procedures for hyperspectral and microwave data.

Dr. Mauser was the Chairman of the National Committee for Global Change Research from 2003 to 2009. From 2014 to 2017, he chaired the European Space Agency's (ESA) Earth Sciences Advisory Committee. He has been involved in major European Research Programs and was appointed as a PI by the ESA for its ERS-1/-2 and ENVISAT Program. 